\title{
Proceeding
}

Supplementary Issue: Rio 2016 Olympic Games First Anniversary Special Edition. Olympic Studies Forum, 4-5 August 2017.

Santa Úrsula University. Rio de Janeiro, Brazil

\section{Center of Physical Education Admiral Adalberto Nunes and the legacy in the Olympic Games "Rio2016"}

\author{
ERIK BUENO DE AVILA \\ Centro de Educação Física Almirante Adalberto Nunes, CEFAN/MB, Brazil
}

\begin{abstract}
This chapter seeks to explore, from the perspective of a Military Organization (OM), an integral part of the structure of the Brazilian Navy, through the Physical Education Center Almirante Adalberto Nunes - CEFAN, during the pre, during and post Olympic Games Rio2016 its preparation and participation , as a Technical Guidance Military Organization (OMOT) in the area of Physical Education and Sports, subsidizing actions of the Command of the Marine Corps (CGCFN), actions to support government agencies, including the Ministry of Sports of Brazil (ME), Brazilian Olympic Committee (COB), Brazilian Paralympic Committee (CPB), National and International Sports Federations and Federations, using its facilities and structures as a base for sports preparation for the 31st Olympic Games of the Modern Era - Rio 2016. Key words: BRAZILIAN NAVY, OLYMPIC GAMES, LEGACY, RIO 2016.
\end{abstract}

\section{Cite this article as:}

Bueno de Avila, E. (2018). Center of Physical Education Admiral Adalberto Nunes and the legacy in the Olympic Games "Rio2016". Journal of Human Sport and Exercise, 13(1proc), S46-S52. doi:https://doi.org/10.14198/jhse.2018.13.Proc1.05

Corresponding author. Centro de Educação Física Almirante Adalberto Nunes, CEFAN/MB, Brazil.

E-mail: EB.Avila@yahoo.com.br

Supplementary Issue: Rio 2016 Olympic Games First Anniversary Special Edition. Olympic Studies Forum, 4-5 August 2017. Santa Úrsula University. Rio de Janeiro, Brazil.

JOURNAL OF HUMAN SPORT \& EXERCISE ISSN 1988-5202

(c) Faculty of Education. University of Alicante doi:10.14198/jhse.2018.13.Proc1.05 


\section{Centro de Educação Física Almirante Adalberto Nunes e o legado nos Jogos Olímpicos "Rio2016"}

\section{RESUMO}

Este capitulo procura explorar, sob a ótica de uma Organização Militar (OM), parte integrante da estrutura da Marinha do Brasil, por intermédio do Centro de Educação Física Almirante Adalberto Nunes - CEFAN, no período pré, durante e pós Jogos Olímpicos Rio2016 a sua preparação e participação, enquanto Organização Militar Orientadora Técnica (OMOT) na área da Educação Física e Esportes, subsidiando ações do Comando do Corpo de Fuzileiros Navais (CGCFN), as ações de apoio aos órgãos governamentais, sendo eles, o Ministério dos Esportes do Brasil (ME), Comitê Olímpico do Brasil (COB), Comitê Paralímpico Brasileiros (CPB), Confederações e Federações esportivas nacionais e internacionais, utilizando de suas instalações e estruturas como base de preparação esportiva para os $31^{\circ}$ Jogos Olímpicos da Era Moderna - Rio 2016. Palavras-chave: MARINHA DO BRASIL, JOGOS OLÍMPICOS, LEGADO, RIO 2016. 


\section{INTRODUÇÃO}

O que o Centro de Educação Física Almirante Adalberto Nunes (CEFAN), da Marinha do Brasil, viu dos Jogos Olímpicos e Paralímpicos Rio2016? Assistiu suas instalações e tripulação serem "permeadas" pelo legado tangível e intangível de um dos maiores eventos esportivos do mundo. "Missão dada é missão cumprida! ADSUMUS".

O Centro de Educação Física Almirante Adalberto Nunes sempre esteve presente no apoio e nas ações do esporte nacional, desde a sua origem, muitas vezes protagonizando ações e profetizando feitos, como por exemplo, quando o Comandante do Centro, à época, no seu posto hierárquico de Capitão de Mar-e-Guerra disse, ao Jornal do Brasil, publicado em 27 de fevereiro de 1973:

Futuramente, quando aparecer algum jovem que sintamos tenha condições de se tornar grande competidor, estaremos preparados para dar-lhe residência, alimentação e trabalho para que possa se dedicar integralmente ao esporte, a exemplo do que acontece nas grandes potências. (Lage, 1973).

Nossa história começa nos anos de 2011/2012, quando o Comitê Organizador Local dos Jogos Rio 2016, fez uma chamada pública para cadastramento de Centros Esportivos como locais de treinamento da delegação brasileira e delegações estrangeiras, como fora de ambientação dessas representações esportivas ao clima local, pré-jogos Olímpicos.

Os Centros Esportivos militares, muitos deles referência no esporte nacional, além de cumprirem todas as exigências necessárias para tal cadastramento, acabaram se destacando como pontos de referência esportiva do próprio Comitê Organizador, por se tratarem de instalações de excelência e estrategicamente bem posicionados nos espaços destinados para as competições dos próprios Jogos como: Região do Maracanã, Região de Deodoro, Região da Barra da Tijuca e Região de Copacabana.

O CEFAN, especialmente localizado na Avenida Brasil, artéria principal de via rodoviária e localizado entre os dois principais aeroportos da cidade do Rio de Janeiro (Santos Dumont e Galeão), serviu de base não só para receber e hospedar delegações estrangeiras como também, delegação esportiva nacional, em especial na preparação dos Jogos.

Já no ano de 2015, como parte integrante do apoio prestado pelo Ministério da Defesa, por intermédio das Forças Armadas, na preparação da cidade do Rio de Janeiro, para mais uma edição dos Jogos Olímpicos de Verão, as Forças Singulares compostas pela Marinha do Brasil (MB), Exército (EB) e Força Aérea (FAB),as pretensões foram confirmadas e o CEFAN oficializou-se como Centro de Treinamento cadastrado pela Organização dos Jogos Rio 2016 e pelo Comitê Olímpico do Brasil como base de apoio dos Jogos Rio 2016.

Contribuir para a transformação do Brasil numa potência olímpica foi à engrenagem mestra do Programa Olímpico da Marinha (PROLIM), criado em 2008 e a força central para que o Centro de Educação Física Almirante Adalberto Nunes (CEFAN) conduzisse seus esforços humanos, materiais e financeiros em proveito do esporte militar e nacional. Foi dentro deste espírito que a Instituição aceitou um grande desafio, uma verdadeira missão, em agosto de 2015, do Ministério do Esporte (ME), ser um dos agentes das Forças Armadas a conduzir o processo de apoio de equipamentos, pessoal e material esportivo para dar suporte aos Jogos Rio2016. 


\section{MÉTODO}

Foi utilizada primeiramente uma revisão de literatura de documentos de candidatura dos locais para treinamento das delegações estrangeiras, divulgadas pelo Comitê Organizador Local dos Jogos Rio 2016, documentos informativos da época (sítios), bem como análise observacional e estudo de caso, vividos in loco, presenciando toda transformação do Centro de Educação Física Almirante Adalberto Nunes antes, durante e depois de sua participação nos Jogos Olímpicos e Paralímpicos Rio 2016.

\section{DISCUSSÃO}

Apresentamos como objetivos tangíveis alcançados todas as melhorias e equipamentos adquiridos pelo Centro, por intermédio do Ministério do Esporte, Comando Geral do Corpo de Fuzileiros Navais (CGCFN) administrador do PROLIM, e executor das ações nas áreas da educação físico e esporte.O sonho de todo atleta de possuir condições adequadas e em igualdade de condições no treinamento com os demais atletas internacionais torna-se realidade, no mínimo para as modalidades que estavam no bojo deste grande processo: Taekwondo, Levantamento de Pesos Olímpico e Paralímpico.

Hoje, a MB possui condições de oferecer os melhores equipamentos e materiais homologados pelas Federações Internacionais para treinamento no CEFAN. Paralelo ao processo de aquisição de equipamentos e materiais foi construído um espaço esportivo específico para a prática destas modalidades no CEFAN, o Centro Nacional de Levantamento de Pesos, que está em plena atividade desde novembro de 2016. Centro dotado de toda a infraestrutura humana e material necessário aos atletas de alto desempenho.

Para as modalidades de Levantamento de Peso Olímpico e Paralímpico foi adquirido todo o material exigido pela Federação Internacional de Levantamento de Peso (IWF) e pelo Comitê Paralímpico Internacional (IPC/PO), que é reconhecido como o órgão regulador do esporte Paralímpico para homologação dos resultados e recordes estabelecidos nos Jogos da Rio2016. Material que, devido a sua qualidade e certificações, poderão mobiliar o Centro de Treinamento do CEFAN e de diversos outros locais do país com excelentes condições técnicas para apoiar atletas de alto rendimento e em desenvolvimento.

O Centro Nacional de Levantamento de Pesos da MB, inaugurado em novembro de 2016, foi dotado com 45 plataformas olímpicas e 10 bancos de supino Paralímpico para atender ao pleno funcionamento e adequado apoio aos atletas. Material que será fundamental para que a Marinha do Brasil contribua de forma significativa para o desenvolvimento destas modalidades esportivas no território nacional.

Trata-se então, do melhor Centro de Treinamento em Levantamento de Pesos da América do Sul.

O CEFAN recebeu para mobiliar seu Centro de Treinamento de Lutas, $80 \%$ de todo o material e equipamento de Taekwondo adquirido para os Jogos Rio2016, que totaliza oito conjuntos de proteção e pontuação da DAEDO, um dos mais modernos equipamentos disponíveis no mercado para a referida modalidade. Material suficiente para mobiliar eventos de cunho internacionais nas dependências deste Centro sem a necessidade de buscar outras parcerias.

A Marinha também apoiou logisticamente o evento quando adquiriu, recebeu, armazenou e manuteniu, operou e posteriormente distribuiu, 90 embarcações de casco semi-rígido (ECSR), de 4 tipos diferentes, adquiridas com recursos do Ministério do Esporte para emprego no apoio à organização dos Jogos, em todas as modalidades aquáticas de águas abertas, como Vela, na Baía da Guanabara, Maratona Aquática 
e Triatlo olímpico e paralímpico em Copacabana e, remo e canoagem olímpicos e paralímpicos na Lagoa Rodrigo de Freitas. Estas embarcações foram empregadas simultaneamente nos mais diversos locais de competições.

\section{Lições aprendidas - pontos negativos e positivos}

O CEFAN tem a certeza de que o esforço empreendido para a realização das aquisições contribuiu para 0 êxito dos Jogos Olímpicos Rio2016 e por meio do legado deixado está contribuindo para a inserção do Brasil no topo do esporte internacional, provendo centros de treinamento de excelência em suas dependências com o melhor material e equipamento disponível no mercado internacional. 0 ciclo olímpico de 2020 teve 0 seu início sinalizado de forma digna e de acordo com a estatura do Brasil no cenário internacional.

A exemplo do que ocorreu com outras Organizações Militares, por exemplo o Exército e a Força Aérea, antes e durante a realização dos Jogos Olímpicos Rio 2016, o CEFAN também serviu como Centro de Treinamento e aclimatação para diversas delegações estrangeiras em várias modalidades esportivas.

No período entre 19 de Julho a 19 de Agosto de 2016 as Seleções Olímpicas de Cuba, Jamaica e Porto Rico realizaram "training camp's" no CEFAN visando à aclimatação de seus atletas para participação nos Jogos Olímpicos Rio 2016.

Adequações e melhorias foram necessárias ao nosso Centro e graças a essas, que se juntaram a outras já existentes (Como exemplo: Escola de Educação Física do Exército - EsEFEx na Urca e Universidade da Força Aérea - UNIFA, em Santa Cruz), também consideradas muito modernas, o CEFAN possui atualmente uma infraestrutura de instalações de treinamento de primeira classe e, por isso, passou a ser considerado um Centro de Treinamento de referência e de excelência, onde atletas de alto rendimento farão a preparação para a 32ª Edição dos Jogos Olímpicos da Era Moderna, em 2020, no Japão.

\section{Caso Cuba}

A seleção cubana de boxe, maior potência mundial da modalidade, realizou no CEFAN a fase de preparação técnica e física, período mais importante no seu ciclo de preparação para os Jogos Olímpicos Rio 2016. As excelentes condições de estrutura de treinamento do CEFAN, associadas ao elevado nível da equipe de boxe da Marinha do Brasil, contribuíram para a equipe cubana de boxe, alcançar seu ápice de desempenho, conquistando 3 medalhas de ouro e 3 medalhas de bronze durante as Olimpíadas.O intercâmbio entre 0 time cubano e o da MB ocorreu em tempo integral, com as equipes realizando toda a preparação técnica e física em conjunto, ocasionando a assimilação por parte de todo o corpo técnico da MB de um inédito legado de metodologia de preparação de campeões olímpicos.

\section{Caso Jamaica}

Os nove ouros olímpicos de Usain Bolt nas provas mais rápidas do atletismo, o credenciaram como uma das principais estrelas dos Jogos Olímpicos Rio2016.Mas antes da disputa dessas provas, no Estádio do Engenhão, Usain Bolt, Asafa Powel, Yohan Blake, Nickel Ashmead, Shelly-Ann Fraser-Pryce, Elaine Thompson e outras estrelas da equipe jamaicana realizaram "training camp" no CEFAN e foi uma honra muito grande receber esses atletas do mais alto nível, que contribuíram para o desenvolvimento do esporte nacional em função da convivência que proporcionaram para os nossos militares e nossos atletas.

Durante o período de treinamento da equipe jamaicana, o astro do atletismo Jamaicano e mundial, Usain Bolt postou em suas redes sociais a foto que tirou com as crianças que pertencem aos Projetos Sociais desenvolvidos no CEFAN. $O$ atleta escreveu na imagem em que as crianças fazem a sua tradicional 
comemoração: "estas crianças residem em comunidades carentes aqui do Rio, mas elas são o nosso futuro e eu estou muito feliz por conhecê-las" (Bolt, 2016).

O CEFAN não estava preparado única e exclusivamente para o treinamento e aclimatação de equipes olímpicas durante o período dos Jogos. O movimento paralímpico também encontrou espaço dentro do Centro de Excelência esportiva da Marinha, com a utilização, nos períodos de 5 a 14 de abril e 30 a 31 de agosto 2016,as Seleções Masculina e Feminina de Basquete em cadeira de rodas do Canadá realizaram seus treinamentos visando à melhor preparação e participação de seus atletas para os Jogos Paralímpicos Rio2016.

A interação com os atletas, por vezes, foi muito maior do que a cessão das instalações e apoio logístico durante o grande evento esportivo que se aproximava. Mostrando que somos muito mais do que uma força de pronto emprego na defesa da soberania nacional, foram programadas visitas aos meios navais e operativos da Marinha do Brasil, como por exemplo, uma visita ao Navio-Aeródromo (NAe) São Paulo (A12), como parte da preparação motivacional dos para-atletas, para que pudessem perceber que as dificuldades à bordo, demonstrando as mesmas exigências existentes em quadra e que para alcançar a vitória é fundamental trabalhar sempre com espírito de equipe.

\section{CONCLUSÃO E CONSIDERAÇÕES FINAIS}

A realização desses dois eventos foi muito importante para o CEFAN, pois exigiu a reforma de algumas instalações, visando à acessibilidade de atletas Paralímpicos, o que capacitou este Centro a sediar treinamentos e/ou competições de outros desportos para atletas com deficiência física.

Não podemos também deixar de considerar como legado o efeito desse treinamento sobre os programas sociais desenvolvidos no CEFAN, pois motivou crianças residentes em comunidades carentes a intensificarem a prática em esportes para no futuro poderem se tornar atletas Olímpicos e Paralímpicos.

Agregado ao fato do uso dos equipamentos e instalações de excelência que o Centro proporciona, mencionamos também o atendimento especializado na medicina e fisioterapia do esporte, proporcionando elogios aos profissionais que ali trabalharam, demonstrando a dedicação e o interesse pela causa do esporte, atendendo e reabilitando muitas vezes as estrelas dos países que ali estavam representados, como o caso da poderosa equipe de atletismo da Jamaica e sua estrela maior, Usain Bolt.

De acordo com os responsáveis pela gerência do esporte militar, o legado ainda inclui a preparação e a formação de atletas, que por meio de federações esportivas, poderão utilizar das modernas instalações dos centros de treinamento da Marinha (CEFAN), do Exército (Centro de Capacitação Física do Exército e Fortaleza de São João e Complexo Esportivo de Deodoro) e da Aeronáutica (Universidade da Força Aérea - UNIFA).

Finalmente um sonho, iniciado sete anos antes de 2016, após uma longa caminhada para a execução e realização dos Jogos Olímpicos, $31^{a}$ edição da era modera os primeiros Jogos da América do Sul, os Jogos Olímpicos "Rio2016", na cidade do Rio de Janeiro - Brasil tornava-se realidade.

A emoção de fazer parte, do maior evento esportivo da terra, é indescritível, emociona apenas de lembrar. Foram momentos que marcaram na memória de cada participante, participando de qualquer função antes, durante e no pós-jogos. 


\section{REFERÊNCIAS}

DaCosta. L. P. (Org.). (2006) Atlas do Esporte no Brasil. Rio de Janeiro, RJ: CONFEF.

Cancella, K., Garrido, F., Ávila, E. B., Soares, V. Q. \& Gross, P. S. C. 100 anos de esporte na Marinha do Brasil: da Liga de Sports ao Programa Olímpico. (1. ed., Vol. 500) Rio de Janeiro: Agência 2A Comunicações.

DaCosta, L. P. (2008) et al. Legados de Megaeventos Esportivos. Brasília: Ministério do Esporte.

Defesa apresenta estratégia para os Jogos Rio 2016 e o legado esportivo. (2015). Recuperado de:

http://www.defesanet.com.br/eventos/noticia/20006/Defesa-apresenta-estrategia-para-os-Jogos-Rio2016-e-o-legado-esportivo/

Documento dos locais de treinamento. (2013). Recuperado de: www.rio2016.com/treinamentoprejogos/documentos

Podium Naval. (2016) Revista do CEFAN/CDM. (n. 3. Ano III.).

Ministério do Esporte. Comitê Organizador do Rio 2016 cadastra 172 Locais de Treinamento Pré-Jogos. (2015). Recuperado de; http://esporte.gov.br/index.php/component/content/article/134-noticias-pan012/36894-comite-organizador-do-rio-2016-cadastra-172-locais-de-treinamento-prejogos

\section{@)}

This title is licensed under a Creative Commons Attribution-NonCommercial-NoDerivs 3.0 Unported License. 